$15^{\text {th }}$ International Conference on

AEROSPACE SCIENCES \& AVIATION TECHNOLOGY,

ASAT - 15 - May 28 - 30, 2013, Email: asat@mtc.edu.eg,

Military Technical College, Kobry Elkobbah, Cairo, Egypt,

Tel: +(202) $24025292-24036138$, Fax: +(202) 22621908

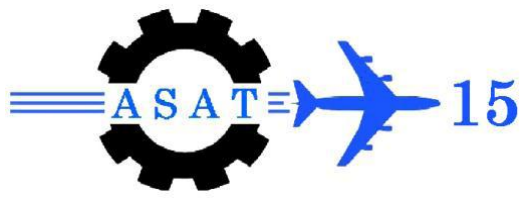

\title{
Study of Performance of Some Selected TBX's
}

\author{
\{A. K. Mohamed, H. E. Mostafa, and M. M. Seleet $\}^{*}$
}

\begin{abstract}
Recently, many countries had motivated new researches in advanced compositions of thermobaric explosives (TBX's) due to its high destructive effects on individuals fortified inside caves and bunkers compared to the limited effects of blast and fragment bombs.

In this paper, EXPLO5 steady state equilibrium program was used to calculate the explosive characteristics and performance parameters for a number of thermobaric explosive formulations based on: mono propellant, as an explosive filler, and aluminum powder as a fuel metal. According to the results of EXPLO5 program some compositions were selected, and according to the possibility of processability conditions, one thermobaric composition was prepared in test cartridges of $2 \mathrm{~kg}$ each. Blasting field area was designed to test the prepared thermobaric charge against a reference TNT charge of the same weight. The pressure-time history, using 12 pressure transducers located at different distances from the explosion center, was measured. The explosion events were monitored by high speed camera while the pressure-time history and positive phase duration were registered by data acquisition measuring system. Test results demonstrated that the positive phase impulse of tested thermobaric explosive charge increased by 10-25\% compared to reference TNT explosive.
\end{abstract}

Keywords: Thermobaric explosives (TBX's), EXPLO5, positive phase impulse.

\section{Introduction}

Over the last decades, Thermobaric explosives (TBX's) had been used effectively by Russian forces in Chechnya and the coalition forces in Afghanistan due to the limited effects of normal blast and fragment bombs on individuals fortified inside caves and bunkers. Thermobaric explosives are designed to increase blast thermal efficiency in comparison to conventional high explosives due to the enrichment of metal fuel. The metal fuel burning in the detonation products with the aid of air oxygen raises the temperature of the gaseous products cloud and strengthens the blast wave. Thermobaric explosives were described in US patents $[\underline{1}, \underline{2}]$ as cylindrical charge shape of annular design containing a core charge of classical high explosive and outer charge of a mixture of fuel and oxidizer with possible addition of binders and catalysts, originally called SFAE (Solid Fuel - Air Explosive) charges. This is useful in military applications where its longer positive phase duration increases the numbers of casualties and causes more damage to structures. There are many different variants of thermobaric weapons rounds that can be fitted to light hand-held launchers, such as rocket-propelled grenades and heavy launched weapons, such as anti-tank weapons and aircraft bombs.

During detonation of TBX charges dual action combustion reactions occurred. Anaerobic combustion reaction (combustion without air oxygen) inside the conventional high explosive of the core, and aerobic delayed burning of the fuel mixture of outer charge which depends

* Egyptian Armed Forces, Egypt. 
mainly on oxygen from the surrounding air. The delayed burning of the metal particles mixed with detonation products leads to an increase of pressure and temperature in the fireball volume. The produced pressure from TBX charges may reach up to four bars and duration time $50 \mathrm{~ms}$ in an environment characterized by high rate of thermal quenching (cold air free explosion) [3]. In the case of confined detonation (in a closed volume), multiple shock reflections enhance the afterburning reactions, and increase both reactivity and thermal effect. Characterization of pressure-time history of TBX and its difference from classical high explosive are represented in figure (1) [3]. The overpressure peak is much higher for the high explosive detonation (P2) than for the TBX detonation (P1), but the former peak drops much more rapidly. The positive phase is followed by a negative phase below atmospheric pressure. The negative phase results in a reversed-blast wind and causes human targets to be bodily lifted and thrown. This phase is longer in TBX detonation than in high explosive detonation. Thus, despite the lower initial blast pressure, the total impulse (represented graphically in Fig. 1, by the area under the curve) can be comparable or even higher for thermobaric explosives compared to high explosives. Target effects are dependent on blast overpressure peak as well as on the duration time (impulse) of the event [3] .

Russian design of thermobaric explosive compositions based on gelled monopropellant (MP) was claimed [4], also the advanced type of US compositions which have the same output were described [2]. The Russian thermobaric composition was a surround charge of aluminum and RDX filled in gelled medium of MP, which dispersed during operation into air already heated by blast wave. Due to the low flash point of MP, it provided extra heat sufficient to ignite the aluminum particles. The advanced US thermobaric warhead was a weak booster surrounded by a charge of aluminum and RDX. Different ingredients, able to perform as thermobaric compositions and raise the effect of particle size of aluminum were claimed [1]. One thermobaric composition based on monopropellant was described briefly [5]. The main ingredients and the effect of monopropellant on the behavior of thermobaric explosive, were described.

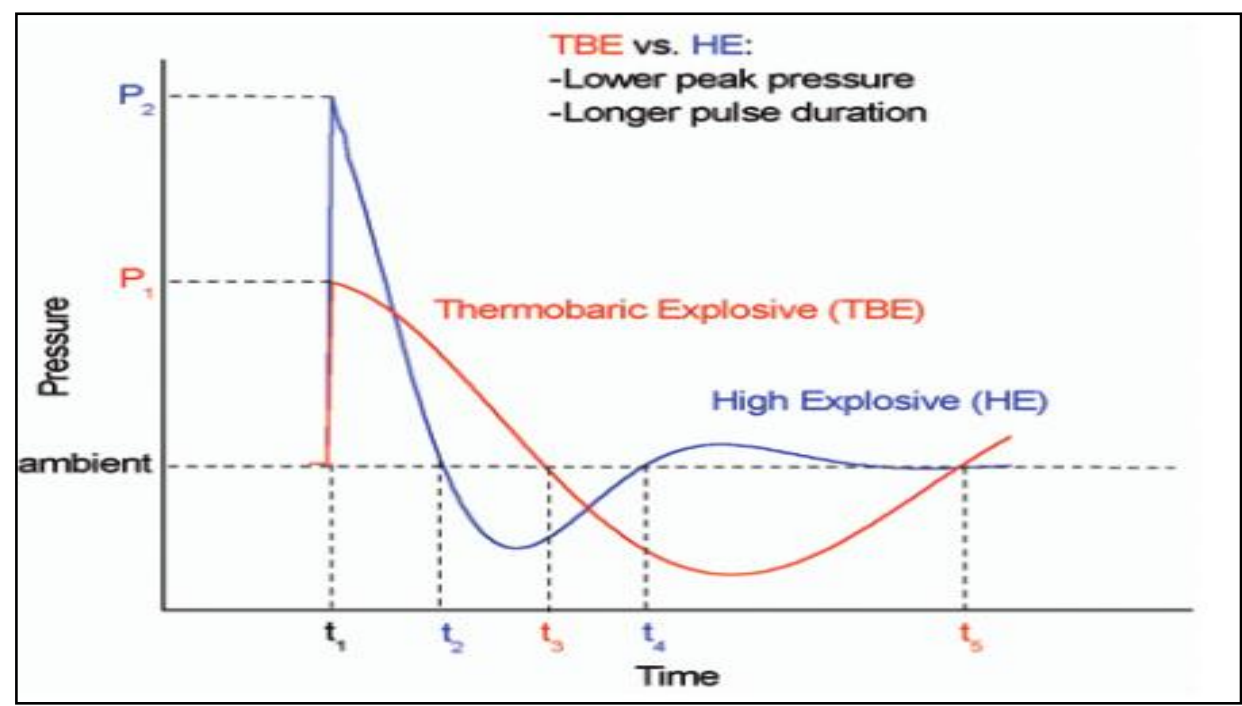

Fig. 1 P-t history for conventional explosion and thermobaric explosion 


\section{Thermochemical Calculation of TBX Formulations}

Thermochemical methods have been used with considerable success as an effective and fast tool to investigate the explosive properties of different types of both single explosive and explosive compositions.

The approach of thermochemical calculations became of great importance for choosing explosive formulations suitable for a given practical application and minimizing much of costly experimental work needed to efficiently evaluate the properties and performance of new explosive compositions []․ The usual starting point for any investigation of a new explosive composition is the prediction of its detonation velocity and Chapman-Jouget (C-J) state properties. Many thermochemical codes are being used nowadays for carrying out thermochemical calculations of the detonation parameters of Energetic materials , such as BKW [7], IDeX [8], TIGER [9], CHEETAH [10], Explo5 [11] which have been developed all over the world.

In this work, two compositions of aluminium were calculated with different RDX and MP content. Explo5 steady state equilibrium code was used for calculation of the detonation parameters for thermobaric compositions. The thermobaric compositions were based on mono propellant, as an explosive filler, and aluminum powder as a fuel metal. The proposed compositions were selected from different references. The C-J detonation calculations for these compositions carried out with the BKWN type equation of state whose constants are shown in table (1). The calculations were made at $90 \%$ of the theoretical maximum density (TMD) of the formulations. Samples abbreviation of the selected formulations and their compositions are shown in Table (2).

Table 1 The set parameters of BKWN EOS used in Explo5 program [12]

\begin{tabular}{c|c}
\hline \hline BKWN Set of parameters & value \\
\hline A & 0.500 \\
\hline B & 0.176 \\
\hline K & 12.90 \\
\hline$\Theta$ & 6620 \\
\hline
\end{tabular}

Table 2 Compositions of TBX formulations

\begin{tabular}{c|c|c|c|c||c|c|c|c|c}
\hline \hline $\begin{array}{c}\text { TBX } \\
\text { Abbrev. }\end{array}$ & $\begin{array}{c}\text { AL } \\
\%\end{array}$ & $\begin{array}{c}\text { MP } \\
\%\end{array}$ & $\begin{array}{c}\text { RDX } \\
\%\end{array}$ & $\begin{array}{c}\text { Facilitating } \\
\text { process } \\
\text { additive }\end{array}$ & $\begin{array}{c}\text { TBX } \\
\text { Abbrev. }\end{array}$ & $\begin{array}{c}\text { AL } \\
\%\end{array}$ & $\begin{array}{c}\text { MP } \\
\%\end{array}$ & $\begin{array}{c}\text { RDX } \\
\%\end{array}$ & $\begin{array}{c}\text { Facilitating } \\
\text { process } \\
\text { addditive }\end{array}$ \\
\hline MP1 & 50 & 40 & 0 & 10 & MP6 & 40 & 45 & 0 & 15 \\
\hline MP2 & 50 & 35 & 5 & 10 & MP7 & 40 & 40 & 5 & 15 \\
\hline MP3 & 50 & 30 & 10 & 10 & MP8 & 40 & 35 & 10 & 15 \\
\hline MP4 & 50 & 25 & 15 & 10 & MP9 & 40 & 30 & 15 & 15 \\
\hline MP5 & 50 & 20 & 20 & 10 & MP10 & 40 & 25 & 20 & 15 \\
\hline \hline
\end{tabular}

where : TBX MP refers to thermobaric formula based on monopropellant 


\section{Experimental Work}

\subsection{Preparation of Thermobaric Charges}

The chemicals used in this work were aluminum powder (H5) of particle size $<32 \mu \mathrm{m}$, waxed RDX, monopropellant (MP) and facilitating process additive. According to the results of EXPLO5 program certain compositions were selected, and according to the possibility of processability conditions, one composition was prepared. The pressing technique was used for the preparation. TBX formulations weights were approximately $2 \mathrm{~kg}$ each. A pressed waxed RDX booster and an RP-7 detonator were used to initiate the charges.

\subsection{Blasting Field Measurement}

\subsubsection{Instrumentation}

In order to record the P-t history of blast waves, the following instrumentations were used: sensor signal conditioner model series 481 containing 16 channels; a bench top data acquisition system (Dewetron), model dewe-5000; PCB Piezoelectric pressure transducers pencil shape, model 137A122 and 137A123; high speed camera recording in max. 675,000 fps, model photron Fastcam SA1.1; and a triggering device.

\subsubsection{Blasting field area layout}

Free air burst was performed for two cylindrical thermobaric explosive charges of $2 \mathrm{~kg}$ each and a reference TNT of the same weight. The charges were located on wooden mount fixed on sturdy wooden stand. The charge center was at $1 \mathrm{~m}$ height from the ground. Care was exercised to ensure that the center of the charge was located at the same height as the transducers. The transducer stands were designed in a way to keep them sturdy in a position to measure the side on pressure. The ground was assessed to be one level at the experiment site. The pressure transducer sensing element was located at distances 3, 5, 6, 7, 8, 9 and10m from the charge. The field layout is shown in Fig. 2.

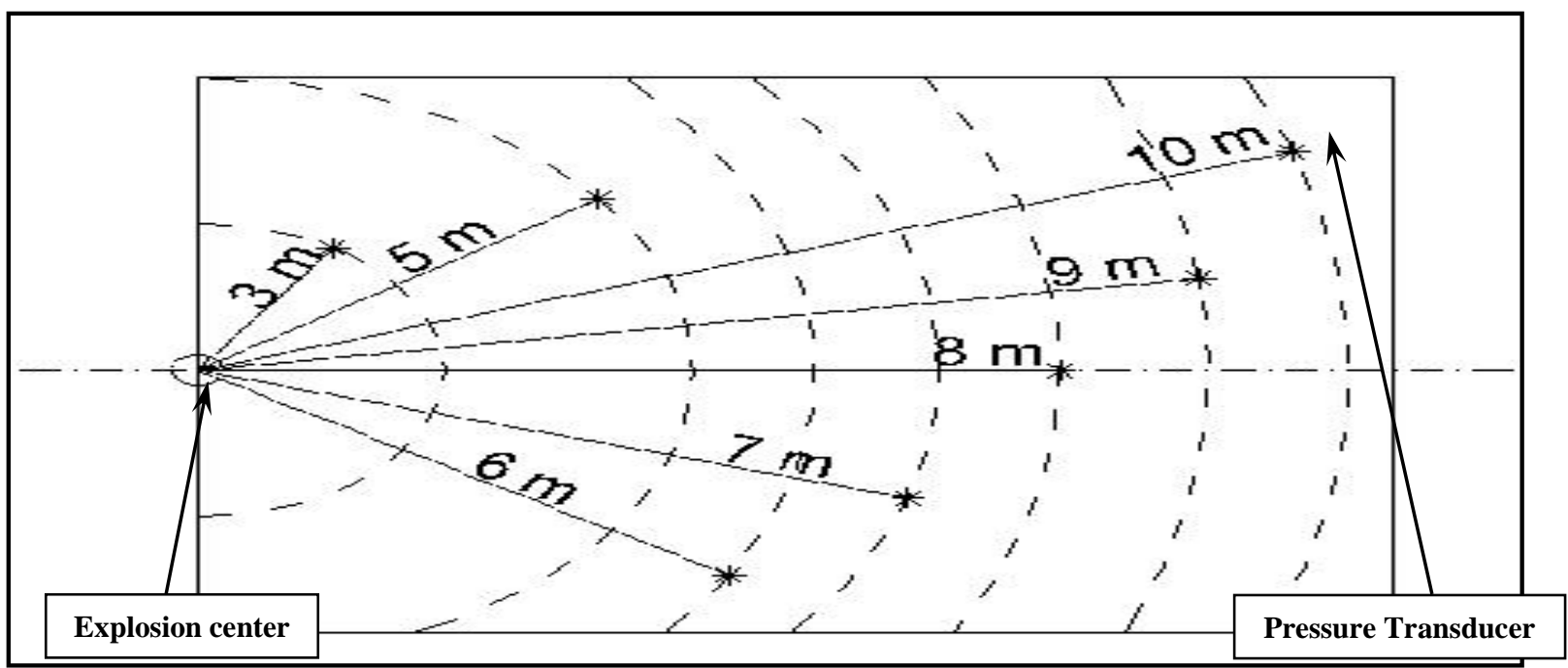

Fig. 2 Layout of blasting field for explosion of thermobaric explosive charges 


\section{Results and Discussion}

\subsection{Thermochemical Calculation Results}

Results of thermochemical calculations for thermobaric compositions shown in table (2) are presented in table (3). The table shows values of the most important explosive characteristics of TBX compositions based on MP compared with the calculated results of TNT charge using the same set of constants.

Table 3 Thermochemical calculation results of TBX formulations based on monopropellant

\begin{tabular}{c|c|c|c|c|c|c|c|c|c|c|c}
\hline \hline \multirow{2}{*}{ Property } & TNT & \multicolumn{7}{|c|}{ Thermobaric formulas based on Monopropellant } \\
\cline { 3 - 11 } & MP1 & MP2 & MP3 & MP4 & MP5 & MP6 & MP7 & MP8 & MP9 & MP10 \\
\hline $\begin{array}{c}\text { Density } \\
\text { [g/cm3] }\end{array}$ & 1.63 & 1.85 & 1.85 & 1.85 & 1.85 & 1.85 & 1.85 & 1.85 & 1.85 & 1.85 & 1.85 \\
\hline $\begin{array}{c}\text { Oxygen } \\
\text { balance }\end{array}$ & -73.94 & -93.95 & -90.1 & -86.2 & -82.35 & -78.4 & -94.9 & -90.08 & -87.2 & -83.34 & -79.48 \\
\hline $\begin{array}{c}\sum \mathrm{n} \\
\text { [per mol } \\
\text { expl] }\end{array}$ & 5.82 & 1.099 & 1.18 & 1.28 & 1.37 & 1.468 & 1.104 & 1.19 & 1.273 & 1.359 & 1.44 \\
\hline $\begin{array}{c}\text { Specific } \\
\text { volume } \\
{[\mathrm{cm} 3 / \mathrm{g}]}\end{array}$ & 574.1 & 372.6 & 370.6 & 369.3 & 367.9 & 367.6 & 334.9 & 334.7 & 333.2 & 333 & 333.1 \\
\hline $\begin{array}{c}\text { Detonation } \\
\text { velocity } \\
{[\mathrm{m} / \mathrm{s}]}\end{array}$ & 6964.4 & 8061.5 & 7992 & 7951 & 7945 & 7936 & 8115.1 & 8001.1 & 7964.1 & 7888.4 & 7824.7 \\
\hline $\begin{array}{c}\text { Pressure at } \\
\text { CJ [kbar] }\end{array}$ & 208.1 & 243.7 & 241.5 & 249.1 & 245.1 & 239.3 & 261.7 & 250.6 & 255.2 & 252.3 & 249.6 \\
\hline $\begin{array}{c}\text { Detonation } \\
\text { heat [kJ/kg] }\end{array}$ & 5407.5 & 4630.8 & 4662.3 & 4695.4 & 4729.1 & 4764.6 & 7815 & 7846.1 & 7879.9 & 7913 & 7947.3 \\
\hline $\begin{array}{c}\text { Temperature } \\
\text { at CJ [K] }\end{array}$ & 2915 & 3332.7 & 3404.8 & 3481 & 3589 & 3675.8 & 4503 & 4569.3 & 4685 & 4782 & 4884.3 \\
\hline \hline
\end{tabular}

\subsubsection{Detonation velocity $(\mathrm{D})[\mathrm{m} / \mathrm{s}]$}

For formulations based on monopropellant, detonation velocity values are shown in figure (3). From the obtained results, we can find that the detonation velocity decreased with decreasing the content of monopropellant and increasing the content of RDX for each aluminum percentage. Also for lower aluminum content of calculated thermobaric formulations, the detonation velocity decreased. However; all TBX compositions have higher detonation velocity than that calculated for TNT. TBX-MP6 has the maximum calculated detonation velocity but according to the difficult processability it couldn't be tested experimentally.

\subsubsection{Detonation heat $(\mathrm{Qv})[\mathrm{kJ} / \mathrm{kg}]$}

Detonation heat values are shown in Fig. 4. The detonation heat increased with decreasing the content of monopropellants and increasing the content of RDX for each aluminum percentage. For formulations of TBX-MP (6-10), the detonation heat has higher values than formulations of TBX-MP (1-5). The values of detonation heat of TBX-MP (1-5) are lower than that calculated for TNT. TBX-MP 10 was selected to be tested experimentally in the field, since it has the highest value of detonation heat. Moreover, it was easily prepared and processed into the required shape. 


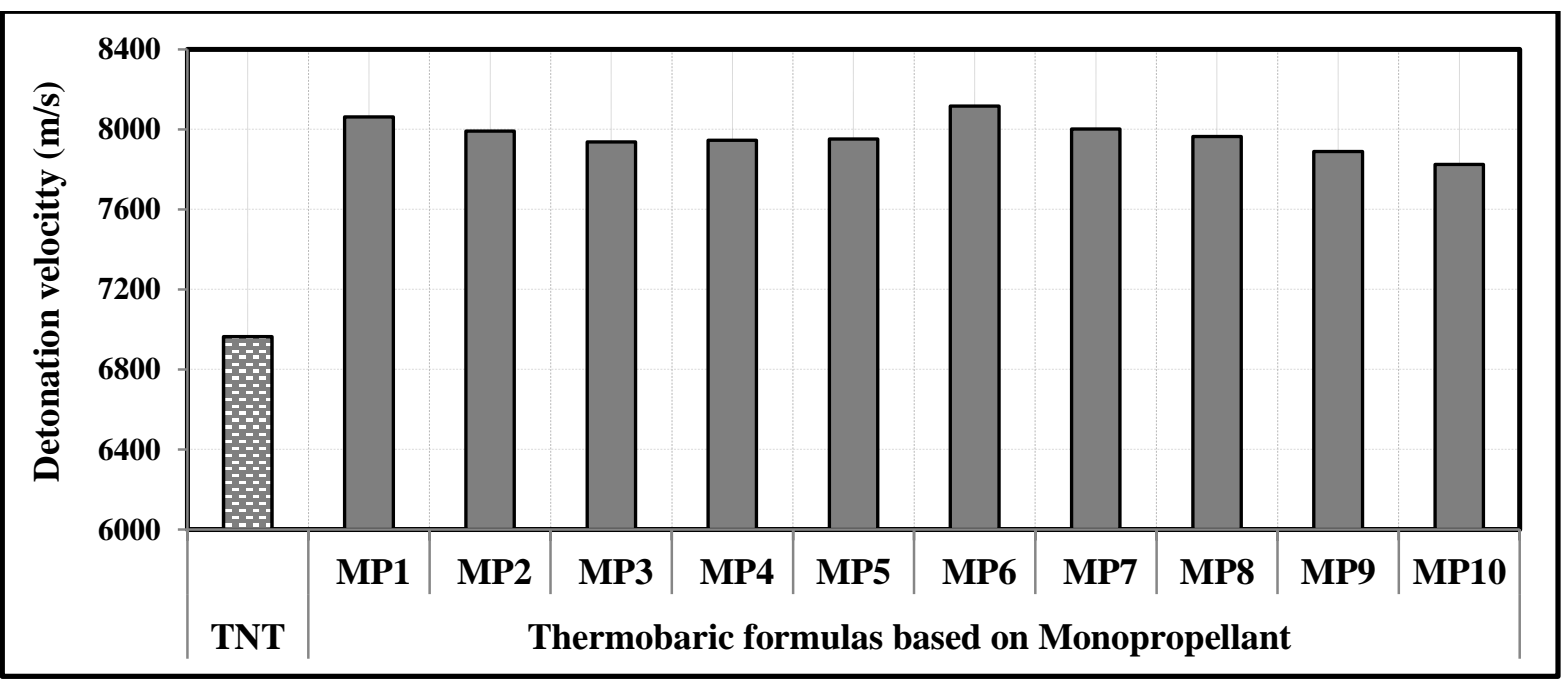

Fig. 3 Calculated detonation velocity values of TBX formulations based on monopropellants

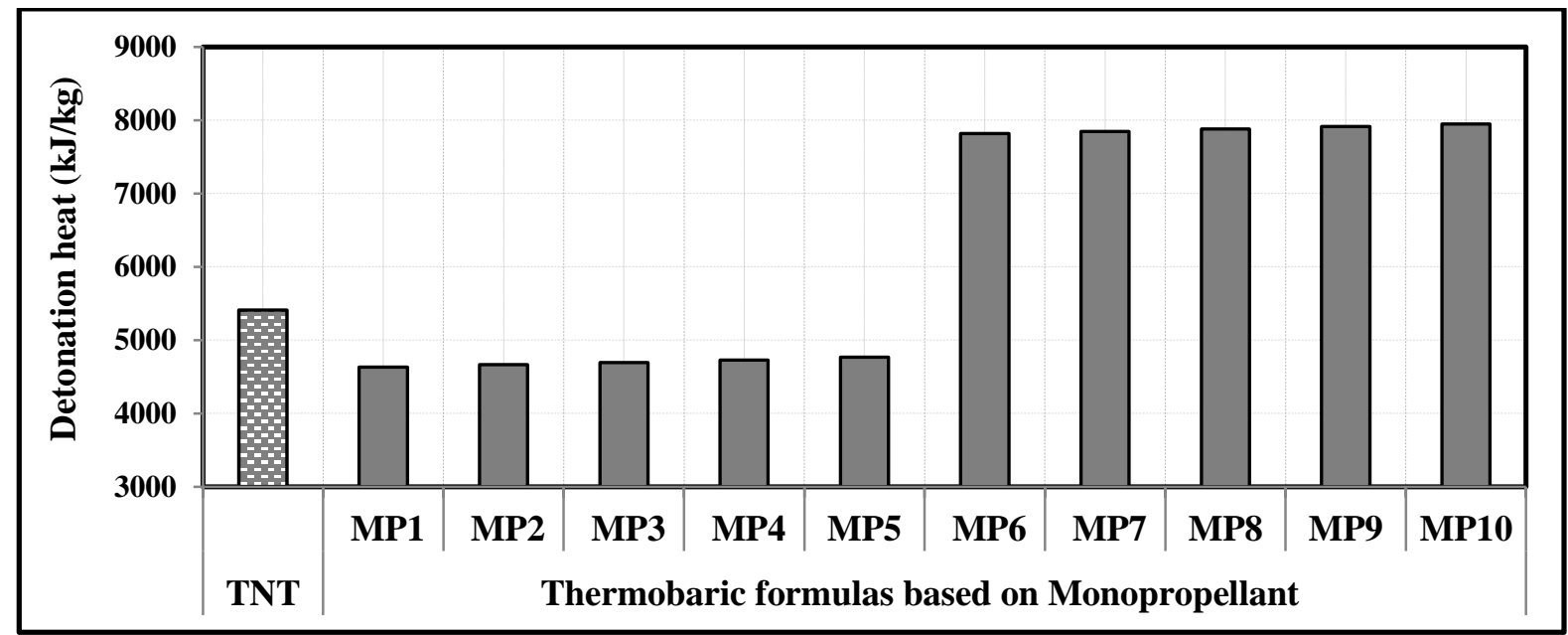

Fig. 4 Calculated detonation heat values of TBX formulations based on monopropellant

\subsection{Experimental Results}

\subsubsection{Shock wave parameters evaluation}

P-t history was registered by the data acquisition system. Three experimental field tests were conducted, two for TBX-MP10 (test 1 and test 2) and one for TNT. Figure 5 shows P-t history for TBX-MP10 composition at $3 \mathrm{~m}$ distance. Similar curves were obtained at other distances of $5,6,7,8,9$ and $10 \mathrm{~m}$. The values of max. positive pressure, Ps+, and positive phase duration, $\mathrm{T}+$ at each distance were determined. Also the positive phase impulse was calculated by the area under the positive phase of P-t history, at each distance. The results are summarized below. 


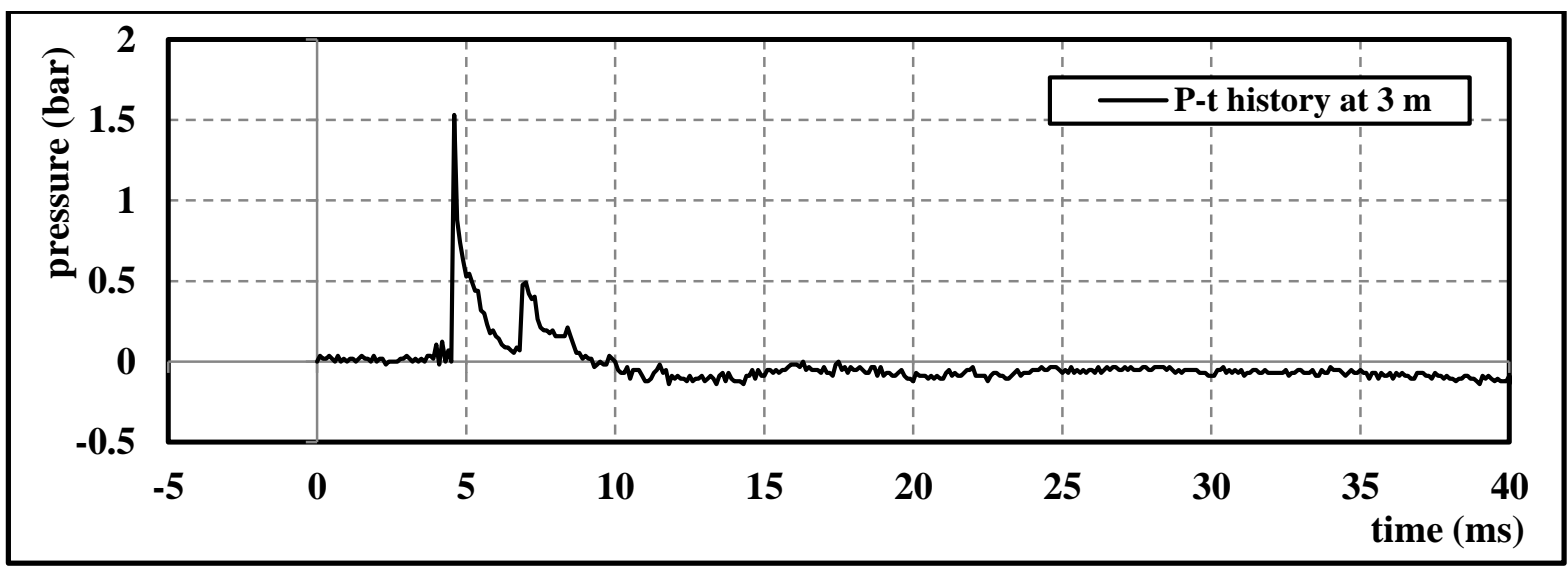

Fig. 5 P-t history for TBX-MP10 composition at $3 \mathrm{~m}$ distance

\section{Maximum positive pressure (Ps+)}

The Max. positive pressures Ps+ vs Scaled distance for tested thermobaric charge and reference TNT charge are shown in Fig. 6. From the results, Ps+ value of test 2 at distance 3 $\mathrm{m}$ from explosion centre is higher than the reference TNT charge and the reason may be related to reflection of the blast wave on the ground. Other values of Ps+ for tests 1 and 2 are similar indicating the good reproducibility of Pressure transduces used in the measurements.

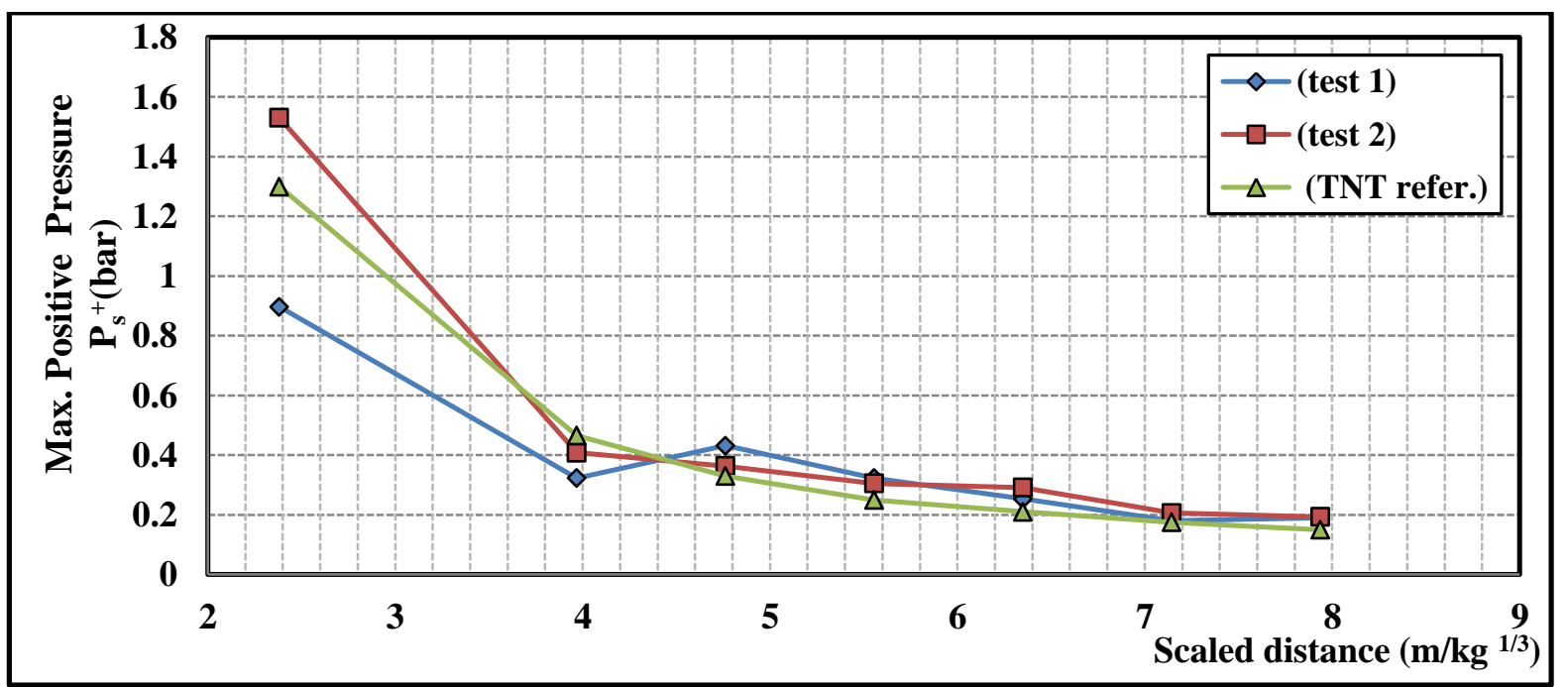

Fig. 6 Max positive Pressure vs scaled distance for tested TBX composition and reference TNT

\section{Positive phase Duration ( $\mathbf{T}+)$}

Figure 7 represents the Positive phase duration $\mathrm{T}+\mathrm{vs}$ Scaled distance for tested thermobaric charge and reference TNT charge. The duration time at distances 3,5 m of test 2 has higher values than test 1 and it may be due to reflection phenomenon mentioned before. For distances 6 and higher, the duration times of test 1 and test 2 are nearly identical. However; the tested thermobaric charge had duration times $20-50 \%$ higher than that of reference TNT charge at all distances. This can be attributed to the presence of $\mathrm{Al}$, which has a longer time of combustion. 


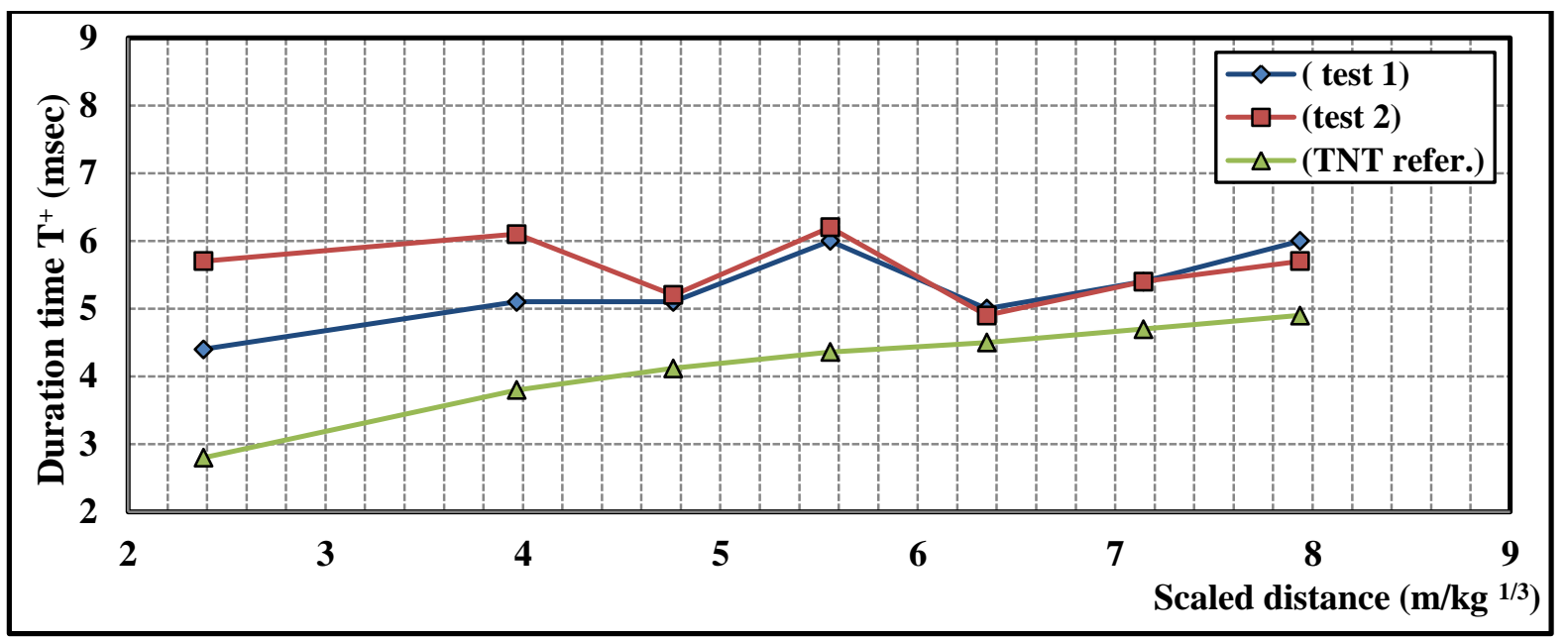

Fig. 7 Positive Phase duration vs scaled distance for tested TBX composition and reference TNT

\section{Positive phase impulse (is+)}

The integration of P-t curves was done to determine the positive phase impulse (is+). The positive phase impulse increased, due to the longer positive phase duration of tested thermobaric charges. Figure 8 represents the Positive phase impulse is+ vs Scaled distance relationship for tested thermobaric charges and reference TNT charge. Although, the high Ps+ and $\mathrm{T}+$ of test 2 at $3 \mathrm{~m}$ the is+ was lower compared with test 1due to the longer decay time of P-t history of test 1 than test 2 . The positive phase impulse of TBX-MP10 increased by 10- 25 $\%$ compared to TNT reference charge.

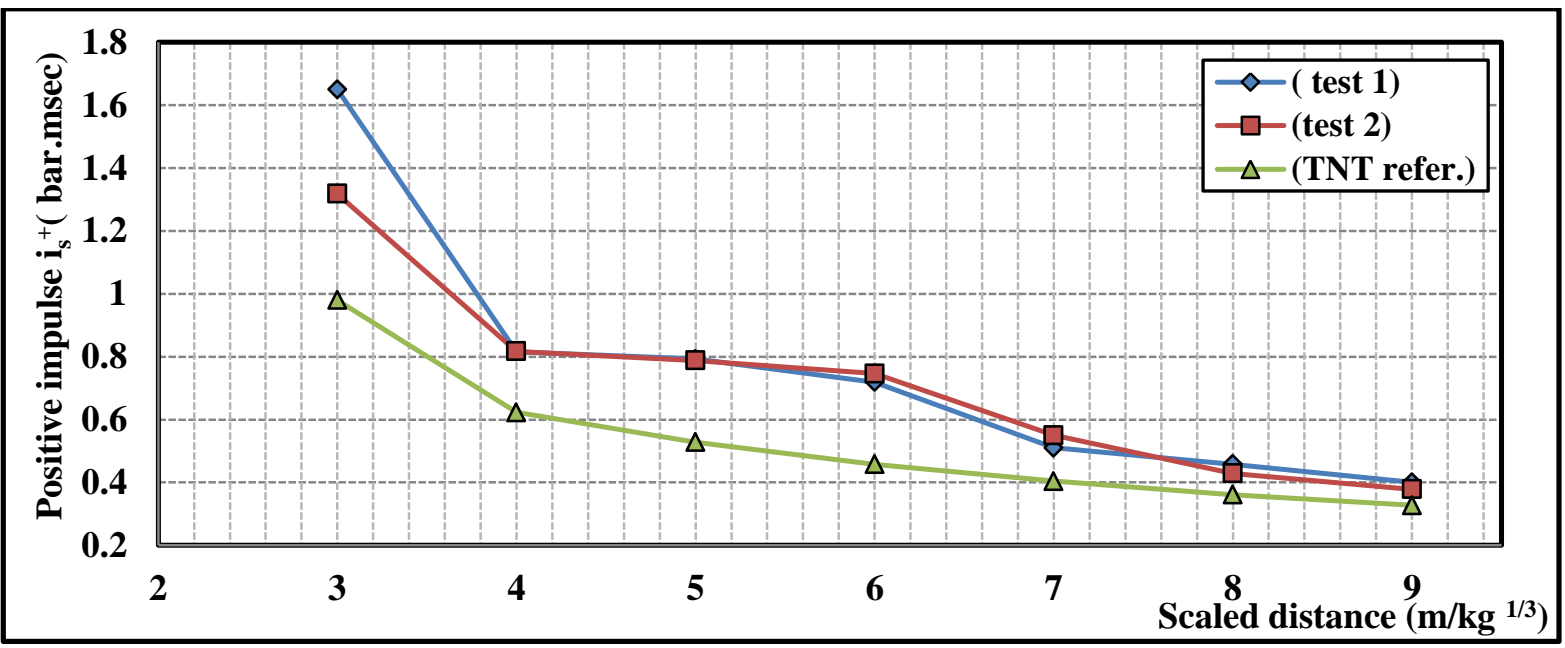

Fig. 8 Positive Phase impulse vs scaled distance for tested TBX composition and reference TNT

\subsubsection{High speed camera results}

High speed camera was used to track the explosion event of the three tests. Figure 9 represents 8 frames of TBX-MP10 for different times from the beginning of explosion till the end of fireball. The width of fire ball was marked by fixed points in each frame to get the maximum dispersion of the fire ball. The frames were registered for 1 millisecond time step. 


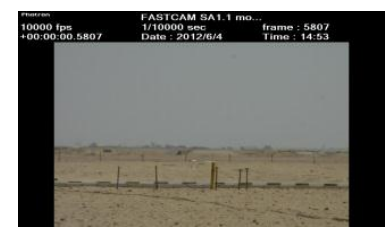

(a)

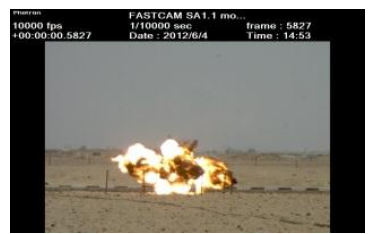

(e)

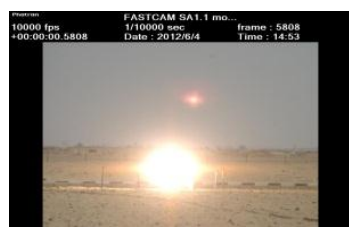

(b)

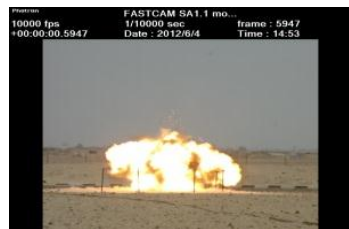

(f)

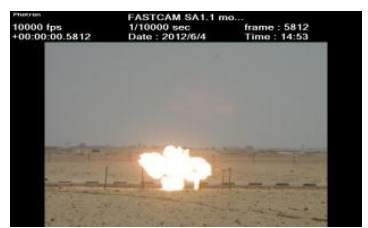

(c)

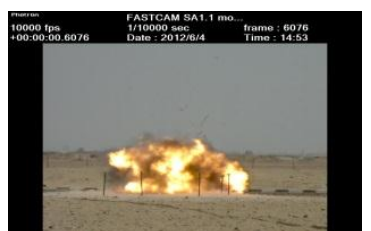

(g)

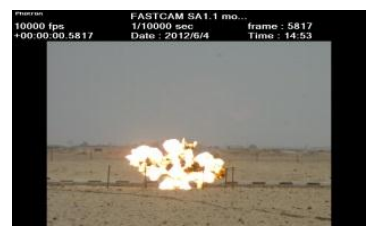

(d)

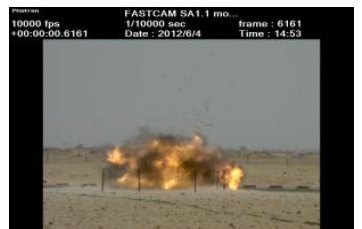

(h)

Fig. 9 High speed frames for 8 different time steps of TBX-MP10

\section{Conclusion}

The EXPLO5 program is a fast and good tool for the calculation of explosive characteristics of new developed compositions. The thermochemical calculation candidate us to select the suitable composition without performing weary and expensive tests. From the Thermochemical calculations, TBX-MP6 compositions had high detonation velocity and TBX-MP10 had high detonation heat. From the processability point of view, TBX-MP10 composition was selected for the blasting field measurement. Test results demonstrated that the positive phase impulse of tested thermobaric explosive charge increased by 10-25\% compared to reference TNT explosive.

\section{References}

[1] May Lee Chan and Gary W. Meyers, "Advanced Thermobaric explosive compositions," Patent US 6,955,732 B1, Oct. 18, 2005.

[2] May Lee Chan, Dung Tri Bui, Gary Meyers, and Alan Turner, "Castable thermobaric explosive formulations," Patent US 6,969,434 B1, Nov. 29, 2005.

[3] Dr Anna E. Wildegger, "Aspects of thermobaric weaponry," ADF Health, vol. 4, no. 34, 2003.

[4] Raafat H. Guirguis, "Reactively induced fragmenting explosives ," patent US 6,846,372 B1, Jan 25, 2005.

[5] Chiris Ludwig, "verifying performance of thermobaric materials for small to medium caliber rocket warheads", Talley defence systems.

[6] N. Desbiens and V. Dubois, "New developements of carte thermochemical code; I paramter optimization," in EPJ web of conferences, Arpajon, France, 2010.

[7] Mader, BKW Hydrocode, 1967.

[8] Freeman et al., IDeX Hydrocode, 1991.

[9] Cowperthwaite and Zwisler, TIGER Hydrocode, 1973.

[10] Fried, CHEETAH Hydrocode, 1995.

[11] Sućeska M., Explo5 Hydrocode, 1991.

[12] Sućeska M, "Calculation of detonation parameters by Explo5 computer program," Material science forum, vol. 465-466, 2004. 